\title{
Levistolide A Induces Apoptosis via ROS- Mediated ER Stress Pathway in Colon Cancer Cells
}

\author{
Yingjuan Yang Yanhua Zhang Lan Wang Shaochin Lee \\ School of Life Science, Shanxi University, Taiyuan, Shanxi, PR China
}

\section{Key Words}

Levistolide A • ROS • ER stress • Apoptosis

\begin{abstract}
Background/Aims: Colorectal cancer (CRC) is one of the leading causes of cancer-related death worldwide. Levistolide $A(L A)$, a natural compound isolated from the traditional Chinese herb Ligusticum chuanxiong Hort, is used for treating cancer. In this study, we investigated the anticancer effect of LA in HCT116 and its isogenic p53-/- colon cancer cells, as well as the underlying mechanisms. Methods: MTT assay was used to evaluate the effect of LA on the viability of cancer cells. Apoptosis and reactive oxygen species (ROS) production by the cells were determined by flow cytometry. Protein expression was detected by western blotting. Results: The results showed that LA inhibited viability and caused apoptosis of both wildtype and p53-/- HCT116 cells. LA was able to trigger production of ROS and endoplasmic reticulum (ER) stress. Inhibition of ROS using $N$-acetylcysteine abrogated LA-induced ER stress and apoptosis, as well as the reduction in cancer cell viability. Conclusion: Our results indicate that LA causes apoptosis of colon cancer cells via ROS-mediated ER stress pathway. It will be interesting to develop the natural compound for chemotherapy of cancers such as CRC.
\end{abstract}

(C) 2017 The Author(s)

Published by S. Karger AG, Basel

\section{Introduction}

Colorectal cancer (CRC) is the second most commonly diagnosed cancer in women and third in men worldwide, with an incidence of 1.4 million new cases and 693,900 of death in 2012 according to the statistics from GLOBOCAN published in 2015 [1]. The major therapeutic regimen includes the combination of surgical procedure and chemotherapy. In the 1990s, targeted therapy was the main direction for development of anti-cancer therapies, and traditional drug screening from natural compounds was left behind. However, targeted 
therapy was soon found to be effective only for the short term, and therapy resistance was obvious. Currently, drug resistance and severe side effects impede the chemotherapy-based treatment strategies for cancer. Thus, there is a need to search for new therapeutic agents with fewer side effects, which target molecular signaling pathways in cancers including CRC. Therefore, in the past decade, natural compounds and their derivatives have come back to the spotlight and have redrawn public attention.

Natural products play a significant role in drug discovery and development, which includes but is not limited to the therapeutic development of anti-cancer drugs. A typical example of therapeutic development using natural product is the use of artemisinin in treating malaria, which has won the Nobel Prize. Notably, natural products and their derivatives are also important for the discovery and development of anticancer drugs due to their unique advantages of low cytotoxicity. Moreover, these products can reverse multidrug resistance of some chemotherapeutic compounds when used in combination [24]. According to a statistics published in 2016, from 1940 through the end of 2014, 49\% of 175 small molecular compounds approved by the US FDA against cancer were natural products or direct derivatives of natural products [5].

The traditional Chinese herb Ligusticum chuanxiong Hort, alone or in combination with other herbs as formula, has long been used for cancer treatment. Moreover, the active components of chuanxiong including sodium ferlate and chuanxiong polysaccharide have shown potential anticancer effects in various cancer cell line models, including the liver cancer cell line HepG2 and human colon cancer cell lines Moser and LoVo. LA is a compound isolated from chuanxiong, polymerized by two molecular ligustilide [6]. Recently, LA has been shown to synergize with vinorelbine in the induction of cancer cell cycle arrest at G2/M phase and apoptosis in breast cancer cells, as well as reverse P-glycoprotein-mediated multidrug resistance in human breast carcinoma cells [7].

In the present study, we aimed to investigate the anti-cancer effects of LA and the underlying molecular mechanism using HCT116 colon cancer cells as an experimental model.

\section{Materials and Methods}

Chemicals and Reagents

Levistolide A (LA, Z, Z, 6, 7-cis, 6. 6, 7. 3a-di (3-butylidene-4,5-dihydrophthalide; Fig. 1A)), a single compound isolated from the traditional Chinese herb Ligusticum chuanxiong Hort, was purchased from PureOne biotechnology (Shanghai, China). A $100 \mathrm{mM}$ stock solution of LA was prepared by dissolving the compound in dimethyl sulfoxide (DMSO) and was kept frozen at $-20^{\circ} \mathrm{C}$ until use. $N$-acetylcysteine (NAC) and methyl thiazolyl tetrazolium (MTT) were obtained from Sigma-Aldrich (St. Louis, MO). The cell cycle and apoptosis analysis kit (cat no: C1052) and DCFH-DA (cat no: S0033) were obtained from Beyotime Biotech (Nantong, China). Antibodies against phospho-PERK, BIP, CHOP, eIF2 , cleaved PARP and GAPDH were purchased from Cell Signaling Technology (Beverly, USA).

Cell Culture and treatment

HCT116 human colon cancer cells were obtained from Cell Resource Center of Chinese Academy of Medical Sciences; its isogenic p53 knockout (p53-/-) cells were kindly provided by Dr. Mian Wu (University of Science and Technology of China). The cells were maintained in DMEM supplemented with $10 \%$ heatinactivated FBS, $100 \mathrm{U} / \mathrm{ml}$ penicillin and $100 \mu \mathrm{g} / \mathrm{ml}$ streptomycin at $37^{\circ} \mathrm{C}$ in a humidified incubator with $5 \%$ $\mathrm{CO}_{2}$ in air. For all experiments, cell cultures at 70-80\% confluence were used. Treatment was performed by direct addition of different concentrations of LA stock solution into the culture media and incubation for 24 $\mathrm{h}$ or $48 \mathrm{~h}$. Cells in the control group were treated with equal amount of DMSO.

Cell viability Assay

Approximately 7,000 cells were seeded in each well of 96-well plates. After $24 \mathrm{~h}$ of incubation, the cancer cells were incubated with the indicated concentrations of LA for another $24 \mathrm{~h}$ or $48 \mathrm{~h}$. Then, 10 


\section{Cellular Physiology Cell Physiol Biochem 2017;42:929-938 \begin{tabular}{l|l|l} 
and Biochemistry & $\begin{array}{l}\text { DOI: 10.1159/000478647 } \\
\text { Published } 2017\end{array}$ & $\begin{array}{l}\text { @ } 2017 \text { The Author(s). Published by S. Karger AG, Basel } \\
\text { www.karger.com/cpb }\end{array}$
\end{tabular}}

Yang et al.: Levistolide A Induces Cancer Cell Apoptosis

$\mu \mathrm{l}$ MTT reagent $(5 \mathrm{mg} / \mathrm{ml})$ was added to each well and incubated for $4 \mathrm{~h}$ at $37^{\circ} \mathrm{C}$ in an incubator after which the medium was removed and $150 \mu \mathrm{l}$ DMSO was added. The culture plates were placed on a shaker for gentle shaking at room temperature for 10-15 $\mathrm{min}$. The absorbance at $570 \mathrm{~nm}$ was recorded on a spectrophotometer.

Lactate dehydrogenase (LDH) release assay

Cell necrosis was evaluated by quantification of plasma membrane integrity monitored by LDH release into the medium. HCT116 cells were seeded in 96-well plates at the density of 7,000 cells per well and then incubated with different concentration of LA $(0,12.5,25,50$ and $100 \mu \mathrm{M})$ for $24 \mathrm{~h}$; DMSO was added to the control wells. LDH released into the supernatant of the culture medium was determined by LDH cytotoxicity detection assay kit (Beyotime, Jiangsu, China) according to the manufacturer's instructions. The necrosis rate was calculated using the equation: (experimental release-control release)/ (maximum release-control release) $\times 100$.

Apoptosis assay

Cell apoptosis was determined by using an annexin V-FITC/PI staining kit (Beyotime Institute of Biotechnology, China) by FACS, following the manufacturer's instructions. Briefly, after treatment, the cells were rinsed twice with cold PBS and then resuspended in $1 \mathrm{X}$ binding buffer at a concentration of $\sim 1 \times 10^{6}$ cells/ml. The cell suspension was incubated with $5 \mu$ lannexin V-FITC for 15 min and $10 \mu$ PI for 5 min at room temperature in the dark and analyzed by flow cytometry within $1 \mathrm{~h}$.

Caspase-3 activity assay

Caspase-3 activity in control and LA-treated HCT116 cells was determined using a caspase-3 activity kit (Beyotime Institute of Biotechnology, China) following the provided instructions. Briefly, cell culture medium was collected and combined with the cells digested by trypsin after $24 \mathrm{~h}$ treatment. After centrifugation, the cell pellets were subjected to lysis by lysis buffer and incubated on ice for 15 min. Lysates were centrifuged at $16,000 \mathrm{~g}$ at $4^{\circ} \mathrm{C}$ for $15 \mathrm{~min}$. Caspase- 3 activity was determined by its catalytic substrate peptides Ac-DEVD- $p$ NA. Release of catalytic production $p$-nitroanilide was quantified by measuring absorbance value at the wavelength at $405 \mathrm{~nm}$.

Quantification of reactive oxygen species (ROS)

Intracellular ROS production was detected by FACSCalibur flow cytometer using the peroxidesensitive fluorescent probe $2^{\prime}, 7^{\prime}$-dichlorofluorescin diacetate (DCFH-DA), according to the manufacturer's instructions. Briefly, after treatment, cells were incubated with $10 \mu \mathrm{M}$ DCFH-DA diluted with serum-free culture medium for $20 \mathrm{~min}$ at $37^{\circ} \mathrm{C}$, then washed three times with serum-free culture medium, re-suspended in ice-cold PBS and kept in dark. The intracellular peroxide levels, which represent the levels of ROS, were measured by an FACS Caliber flow cytometer that emission wavelength at $525 \mathrm{~nm}$. 10,000 individual cells for each group were acquired using the CellQuest ${ }^{\mathrm{TM}}$ software (BD Biosciences, CA) and analyzed by the FlowJo 7.6 software (TreeStar, San Carlos, CA).

\section{Western blot analysis}

Cells were washed twice with cold PBS and lysed with ice-cold modified RIPA buffer $(25 \mathrm{mM}$ Tris· $\mathrm{HCl}$, $\mathrm{pH} 7.4,150 \mathrm{mM} \mathrm{NaCl}, 1 \mathrm{mM}$ EDTA, 1\% NP-40, and 5\% glycerol) containing phosphatase and protease inhibitors cocktail (Thermo Fisher Scientific, Rockford, IL). Whole cell lysates were centrifuged for $25 \mathrm{~min}$ at $13,000 \mathrm{~g}$ at $4^{\circ} \mathrm{C}$, supernatants were collected, and protein concentration was determined using BCA protein assay (Bio-Rad Laboratories, Hercules, CA). Proteins were separated on 10\%-12\% reducing SDS-PAGE and electroblotted onto Immobilon-P polyvinylidene fluoride membranes. Immunoblots were blocked with 5\% non-fat dry milk in tris-buffered saline and $0.05 \%$ tween 20 (TBST) for 60 min at room temperature and incubated overnight at $4{ }^{\circ} \mathrm{C}$ with the indicated primary antibodies. Blots were washed in TBST and incubated with Horseradish peroxidase-conjugated secondary antibodies (1:20,000, Pierce, Rockford, IL, USA) for 1 $\mathrm{h}$ at room temperature. Antigen-antibody complexes were visualized by chemiluminescence using ECL kit (Pierce Rockford, IL, USA). All primary antibodies were purchased from Cell Signaling Technology (Beverly, MA, USA).

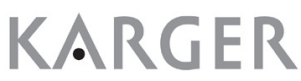


Statistical Analysis

The data are presented as the mean \pm SD. Student's T-test was performed for comparison of two datasets. One-way or two-way ANOVA was performed for multiple comparisons of datasets. Prism 6.04 (Graph Pad Software Inc., San Diego, CA) was used for statistical analyses. $P<0.05$ was considered statistically significant.

\section{Results}

LA suppresses the survival of HCT116 cell lines in a time- and dose-dependent manner

To determine the effects of LA on the growth of human colon cancer cells, HCT116 and its isogenic p53-/- cells were treated with different doses of LA for $24 \mathrm{~h}$ or $48 \mathrm{~h}$, and MTT assay was performed to investigate cell viability. DMSO was used as vehicle control for LA. The clinical drug 5-fluorouracil (5-FU) was used as positive control. As shown in Fig. 1B, treatment with LA inhibited the viability of both HCT116 wild type and HCT116 p53-/- cells in a dose- and time-dependent manner.

\section{LA induces apoptosis in cancer cells}

We tested whether LA could cause necrosis of cancer cells by measuring LDH release by the cells $24 \mathrm{~h}$ after LA treatment (Fig. 1C). The results showed that low levels of LDH release occurred upon LA treatment-approximately $6.95 \%$ and $8.33 \%$ when incubated with 50 and $100 \mu \mathrm{M} \mathrm{LA}$, respectively. We further examined the pro-apoptotic effect of LA on cancer cells. HCT116 and its isogenic p53-/- cells were treated with different concentrations of LA for $24 \mathrm{~h}$, and apoptosis was detected by annexin V-FITC/PI staining in combination with flow cytometry. As shown in Fig. 2A and B, a dose-dependent increase in the fraction of apoptotic cells was observed in HCT116 cells, and the proportions of annexin V-FITC and PI doubly stained cells were $7.1 \%, 10.9 \%$ and $27.3 \%$ in the control, low LA (50 $\mu \mathrm{M})$ and high LA $(100 \mu \mathrm{M})$ groups, respectively. In accordance with the MTT results, a reduced apoptotic

Fig. 1. Viability of HCT116 cells was inhibited by LA in a time- and dose-dependent manner. (A) Chemical structure of LA. $\left(\mathrm{C}_{24} \mathrm{H}_{28} \mathrm{O}_{4}\right.$, MW=380.48). (B) HCT116 and HCT116 p53-/- cells were treated with different concentrations of LA $(0,25,50,100$ and $200 \mu \mathrm{M})$ for $24 \mathrm{~h}$ and $48 \mathrm{~h}$. The cells were harvested and cell viabilities in response to the indicated treatments were assessed by MTT assay. ${ }^{*} P<$ 0.05 and ${ }^{* *} P<0.001 . \mathrm{n}=6$, the experiments were repeated 4 times. (C) LDH release from HCT116 cells treated with LA $(12.5,25,50$ and $100 \mu \mathrm{M}$ ) for $24 \mathrm{~h}$.

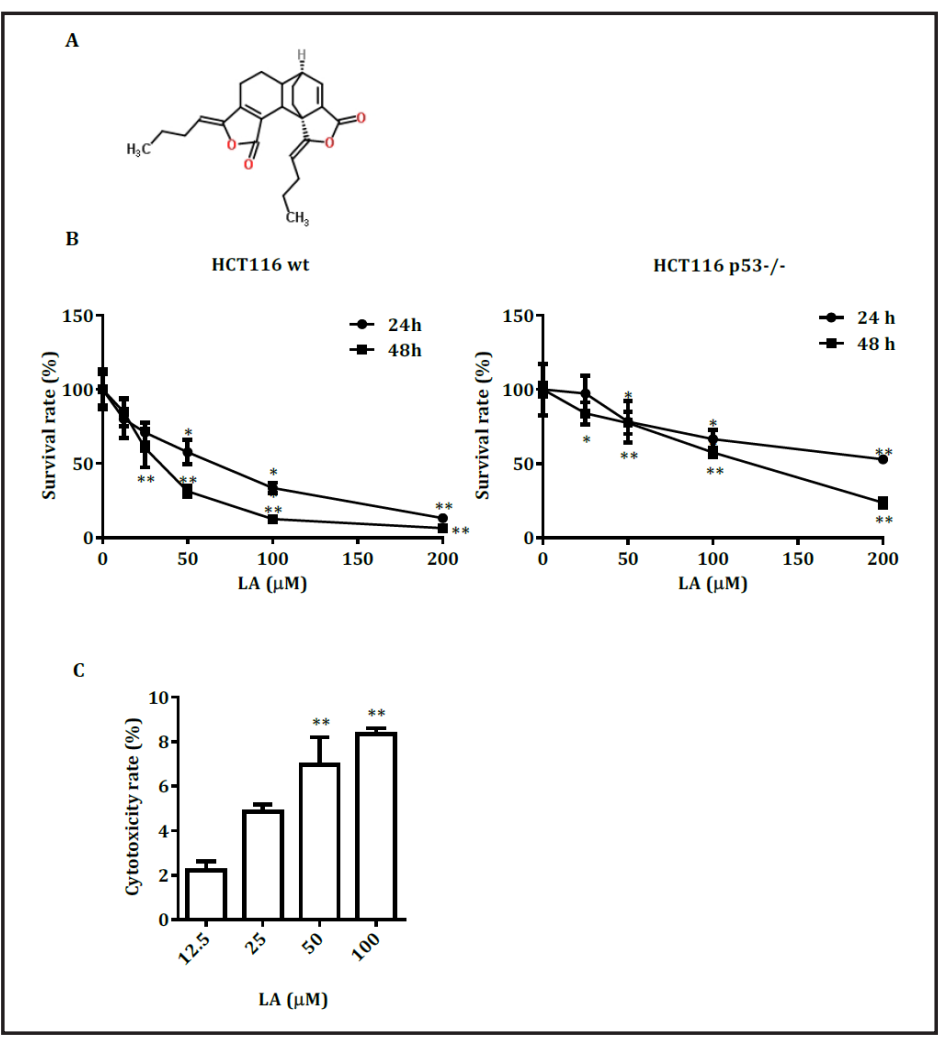


Fig. 2. LA treatment induces apoptosis in HCT116 cells. (A) HCT116 and p53-/HCT116 cells were treated with the indicated concentrations of LA for $24 \mathrm{~h}, 5$-FU was used as the positive control. Apoptosis was determined by annexin V-FITC/ PI staining and flow cytometry. (B) Percentage of apoptotic cells was calculated according to the flow cytometry results after $24 \mathrm{~h}$ of LA-treatment in both HCT116 and p53-/- HCT116 cells. The data presented are representative of three independent experiments. (C) Histograms are shown for the percentage of apoptotic cell population after $48 \mathrm{~h}$ of LA-treatment in both wild-type and p53-/HCT116 cell lines. (D) Caspase- 3 activity was assessed in the control and LA-treated HCT116 cells. (E) The protein expression of cleaved PARP was de-

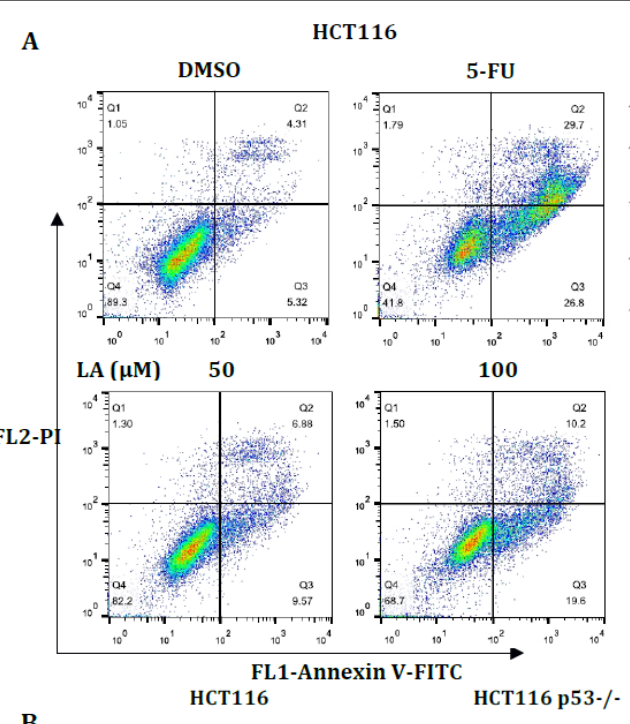

B

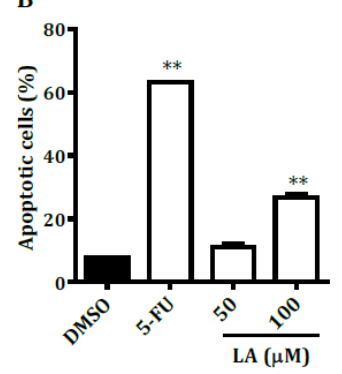

C
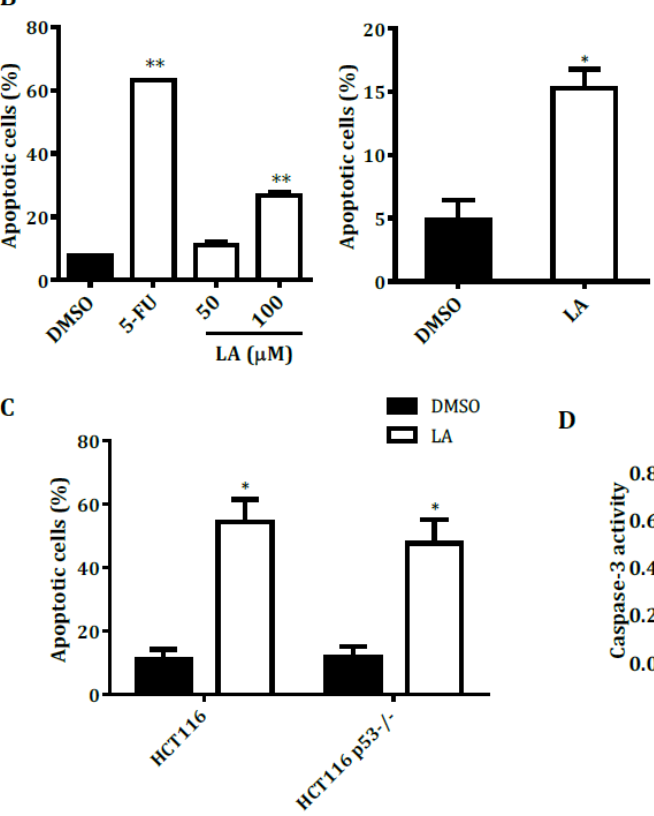

D

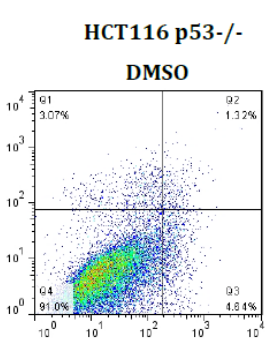

LA

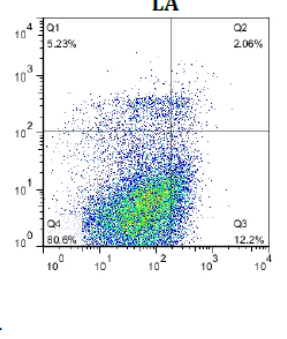

E

DMSO LA

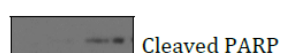

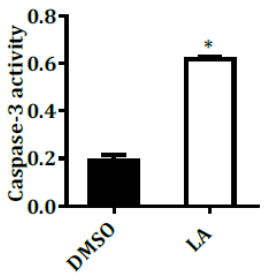

tected via western blotting in HCT116 cells. GPADH was used as the loading control. $* P<0.05$ and ${ }^{* *} P<$ 0.001 .

rate $(\sim 15 \%)$ was observed in the p53-/- HCT116 cells compared with $27.3 \%$ in HCT116 cells after $24 \mathrm{~h}$ LA-treatment, which increased to approximately 42\% in p53-/- HCT116 and 55\% in HCT116 cells during 48 h LA-treatment (Fig. 2C). To further confirm that LA can trigger apoptosis, we determined the activity of apoptosis executioner, caspase- 3 . The results showed that caspase- 3 activity was significantly up-regulated by LA in the cancer cells (Fig. 2D). Furthermore, we demonstrated that LA induced the cleavage of PARP, which is a substrate of caspase-3 (Fig. 2E).

\section{LA increases ROS production in cancer cells}

Studies have suggested that ROS are an important modulator of the response to cancer therapeutic agents [8]. We therefore determined whether ROS generation is involved in the growth inhibition and pro-apoptotic effect elicited by LA. As shown in Fig. 3, ROS production was increased by LA in a dose-dependent manner. Pretreatment of the cancer cells with 5 
Fig. 3. LA triggers ROS generation in HCT116 cells. (A) Dose-dependent generation of cellular ROS induced by LA. HCT116 cells were treated with the indicated concentrations of LA (50 and $100 \mu \mathrm{M}$ ) for $24 \mathrm{~h}$, and cellular ROS levels were evaluated using DCFH-DA via flow cytometry. (B) The effect of NAC on LA-induced ROS generation. HCT116 cells were pretreated with $5 \mathrm{mM} \mathrm{NAC}$ for $1 \mathrm{~h}$ prior to LA (100 $\mu \mathrm{M}$ ) treatment. Cellular ROS levels were measured according to a previously described method. Rosup was used as the positive control. The data are representative of three independent experiments.

mM antioxidant NAC completely abolished LA-mediated ROS generation.

\section{LA induces ER stress in cancer cells}

Recently, studies showed that ER stress can be activated as a downstream event of oxidative stress-mediated apoptosis, and in several instances, both of these processes can occur together [9-11]. To investigate the role of ER stress in LA-induced apoptosis, the expression of ER stress-related proteins, including Bip, p-eIF2 $\alpha$, and CHOP was measured by western blot analysis. The results showed that LA treatment significantly activated ER stress, as evidenced by the increase in the expression of ER stressrelated proteins (Fig. 4). The expression of molecular chaperone Bip was increased by LA in a dose-dependent manner, and the phosphorylation of eIF2 $\alpha$ was also increased by LA. Moreover, enhanced expression of the downstream response product of ER stress CHOP was observed.

ROS signal is upstream of ER stress in apoptosis induction by $L A$

To test whether ROS are a signal for apoptosis, we treated cells with the ROS scavenger NAC ( $5 \mathrm{mM})$ for $1 \mathrm{~h}$ prior to LA and quantified cell viability and apoptosis. The results showed that treatment with NAC,

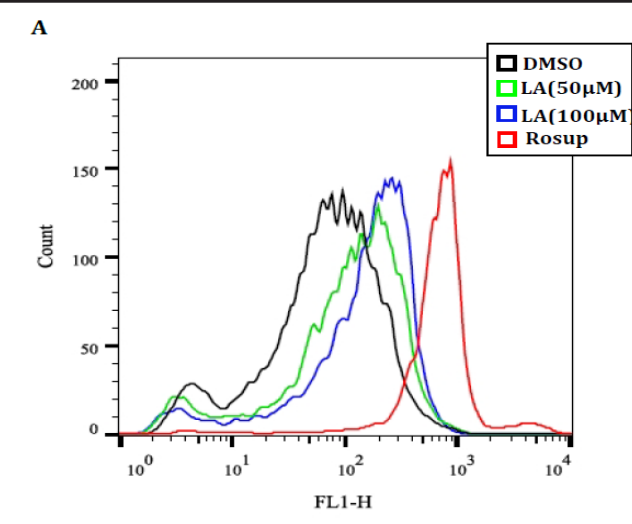

B
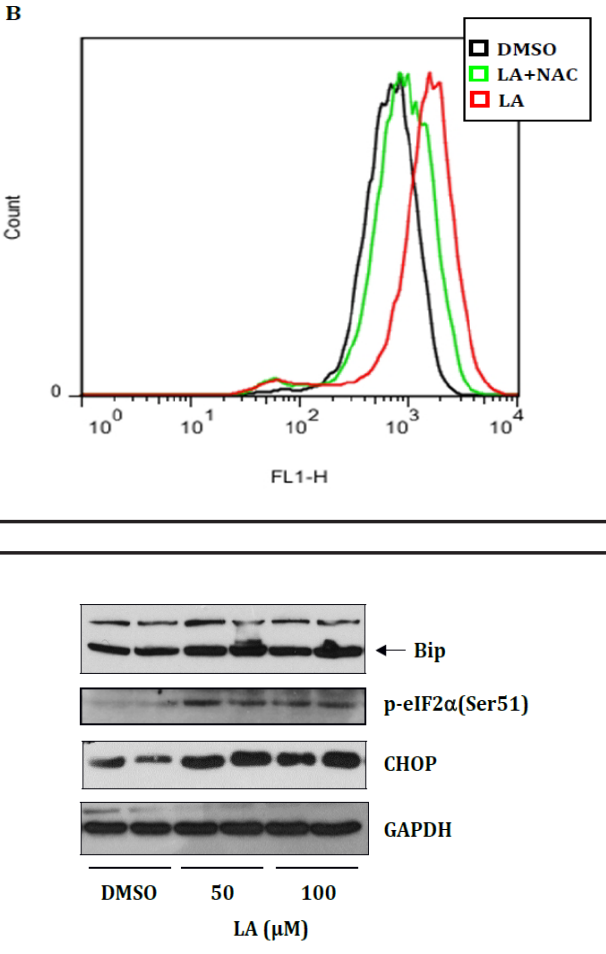

Fig. 4. The induction of ER stress pathways by LA treatment in HCT116 cells. HCT116 cells were treated with the indicated concentrations of LA for $24 \mathrm{~h}$, and the protein levels of ER stress markers including Bip, p-eIF $2 \alpha$ and CHOP were determined by western blotting. GAPDH were used as the internal control. The data presented are representative of three independent experiments.

while preventing ROS generation (Fig. 3B) was able to abrogate the inhibitory effect of LA on cell viability (Fig. 5D, E) and apoptosis (Fig. 5A, B). More specifically, the proportion of apoptotic cells in the control cells, LA-treated cells and those treated with LA plus NAC was approximately $11.6 \%, 41.04 \%$, and $22 \%$, respectively.

In different studies, ROS have been shown to be upstream or downstream of ER stress [9, 12-15]. To clarify whether ROS are upstream or downstream of ER stress in LA-induced apoptosis, we tested whether NAC could inhibit ER stress signals. The results showed that after blockage of ROS production by NAC, the LA-induced activation of ER stress was 


\section{Cellular Physiology

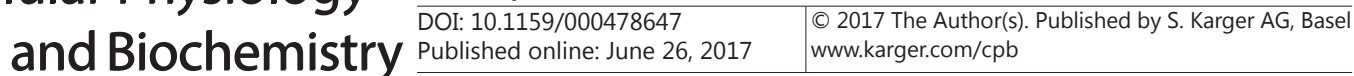 \\ Yang et al.: Levistolide A Induces Cancer Cell Apoptosis}

Fig. 5. Pretreatment with ROS scavenger NAC abrogated LA-induced apoptosis and activation of ER stress. (A) HCT116 cells were pretreated with $5 \mathrm{mM}$ NAC for $1 \mathrm{~h}$ prior to LA treatment; cells were incubated with LA alone or in combination with NAC for $24 \mathrm{~h}$ then stained with annexin V-FITC/ PI and analyzed by flow cytometry. (B) Apoptotic cells were calculated according to the flow cytometry results and graphed with GraphPad Prism 6. The percentage of apoptotic cells is representative of three independent experiments and expressed as the mean $\pm \mathrm{SD} .{ }^{*} P<0.05$ or ${ }^{* *} P<0.001$ (C) HCT116 cells were treated with LA alone $(50 \mu \mathrm{M}$ and $100 \mu \mathrm{M})$ or in combination with NAC for $24 \mathrm{~h}$, then the protein expression of ER stress markers (Bip, p-eIF $2 \alpha$ and CHOP) was determined by western blotting. GAPDH was used as the loading control. (D) The cells were examined by phase-contrast microscopy. Scale bars = $500 \mu \mathrm{m}$. (E) The cell viability in response to the indicated treatment was assessed by MTT assay. ${ }^{*} P<0.05 . \mathrm{n}=5$, experiments were repeated 3 times.

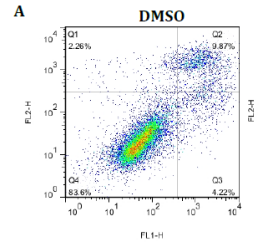

B
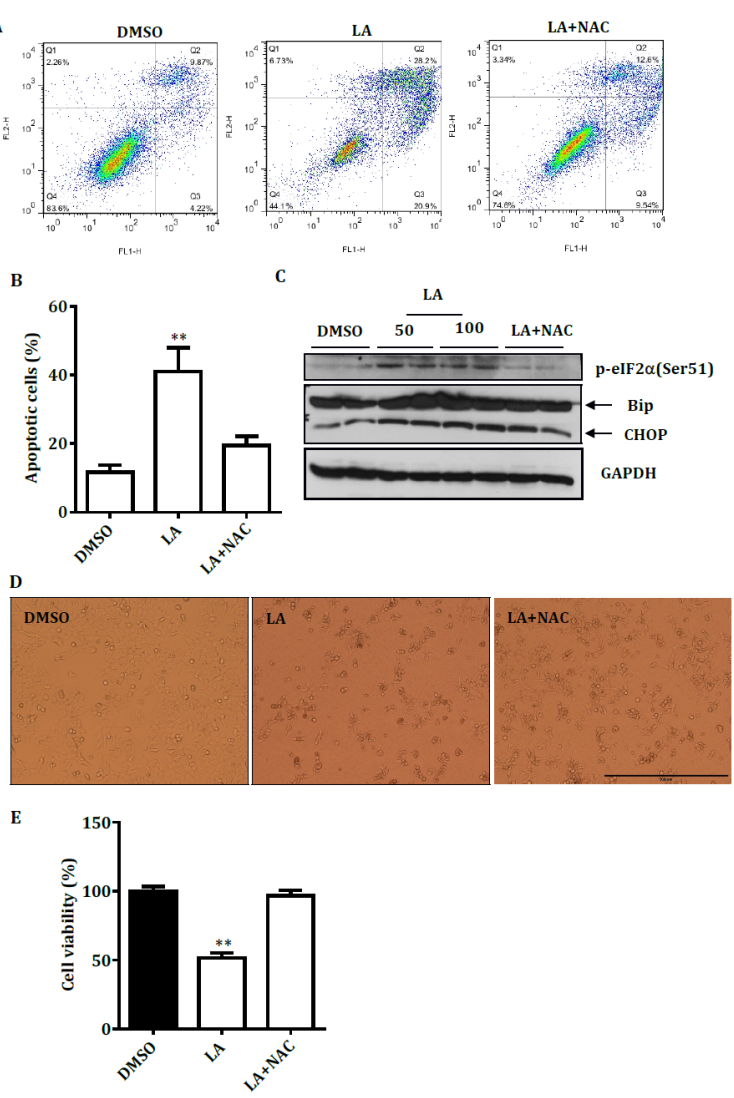

inhibited. More specifically, NAC inhibited the LA-induced up-regulation of Bip, p-eIF2 $\alpha$ and CHOP (Fig. 5C).

\section{Discussion}

A previous study showed that the chloroform extracts from Angelicae sinensis, ligustilide, can reverse P-glycoprotein-mediated MDR in human breast carcinoma Bcap37/MDR1 cells and enhance the apoptotic effects of the chemotherapeutic drugs adriamycin and vincristine. The IC50 of LA was 89.31 and $93.14 \mu \mathrm{mol} / \mathrm{L}$ in Bcap37 and Bcap37/MDR1 cells, respectively [7]. In the present study, we demonstrated that LA can inhibit the viability of human colon cancer HCT116 cells in a time- and dose-dependent manner (Fig. 1B) and induce apoptosis of the cancer cells (Fig. 2), indicating that LA can be a candidate anticancer agent against human colon cancer. Thus, it will be interesting to investigate the anti-cancer activity of LA in vivo in animal models. Moreover, since the tumor suppressor gene p53 plays a pivotal role in cancer development and mutations of the p53 gene occur in most CRCs, we further investigated LA-induced apoptosis in isogenic HCT116 p53-/- cells; the results showed that knockout of p53 decreased the sensitivity of the cells to drugs, which is consistent with our previous findings and those of many other studies [16,17].

Cancer cells are characterized by elevated level of ROS due to imbalanced redox homeostasis [18]. ROS play a controversial role in tumor progression and metastasis. Low to moderate levels of ROS may contribute to tumorigenesis, but excessive ROS production promotes cancer cell death [8]. Therefore, targeting ROS is an important anticancer therapeutic strategy. In fact, a large number of studies have demonstrated the induction of ROS-mediated apoptosis by various therapeutic drugs [19-21]. In this study, we found that LA triggered ROS generation (Fig. 3) and apoptosis (Fig. 2), both of which were inhibited by 
the antioxidant NAC (Fig. 5A, B), indicating that ROS are a signal that mediates LA-induced apoptosis. Normal ROS homeostasis is crucial for maintaining normal cell function. ROS are mainly produced in the mitochondria through metabolic reactions, in peroxisomes through $\beta$-oxidation of fatty acids and in the ER through protein oxidation [22]. Recently, ER stress inducers have drawn attention as potential anticancer drugs by inducing cancer cell death since ER stress can cause apoptosis in cancer cells [23]. Compelling evidence has demonstrated that both ROS generation and ER stress activation can be induced upon therapeutic treatment [24]. Evidence has shown that ER stress is a common response mechanism upon treatment with therapeutic agents. Thus far, dozens of drugs targeting the ER stress pathway have been approved by the FDA, including 5 -fluorouracil, arsenic trioxide and bortezomib. ER stress disrupts cellular homeostasis by promoting the accumulation of misfolded or unfolded proteins within the ER lumen, leading to the activation of UPR aiming to restore ER homeostasis. The evolutionarily conserved UPR signaling pathway is regulated by three transmembrane proteins, namely, PERK, IRE1 $\alpha$ and ATF-6 [25]. Among these, the PERK-mediated branch is the most commonly studied. ER stress is initiated with the sequestration of the ER resident chaperone Bip. Release of Bip results in the activation of PERK. Activated PERK phosphorylates eIF2 $\alpha$, which in turn activates the downstream transcription factors ATF4 and CHOP. CHOP is also known as a growth arrest and DNA damage gene 153, which acts as an executioner of the pro-apoptotic branch of ER stress [26, 27]. CHOP mediates cell death through various targeted transcriptional factors, including GADD34, Ero1L, Bim and DR5 [28-30]. Here, we explored the potential role of ER stress upon LA treatment in HCT116 cells. The results showed that LA activated the PERK/eIF2 $\alpha$ / CHOP axis, as evidenced by the enhanced protein expression of phosphorylated PERK and eIF $2 \alpha$ as well as CHOP, which plays a convergent role in ER stress-mediated apoptosis and is activated by all three arms of ER stress sensors. Caspase-12 is localized to the ER and plays a central role in ER-stress-mediated apoptotic cell death [31]. However, it has also been reported that ER stress induces apoptosis in an apoptosome-dependent and caspase-12independent mechanism in mice [32]. Our results showed that the activity of caspase- 3 is up-regulated by LA (Fig. 2D), whereas the activation of caspase-12 is not a significant event (data not shown), suggesting that LA induces apoptosis through the ER stress pathway that is independent of caspase- 12 .

Several groups have reported that ER stress increases ROS and antioxidants protect cells from ER stress-induced cell death $[14,15]$. In our study, ROS generation was increased by LA in a dose-dependent manner, and blocking ROS production by NAC almost completely abrogated LA-induced apoptosis and dramatically attenuated LA-induced Bip, PERK and CHOP expression, indicating that ROS generation is an upstream event of ER stress induced by LA. The interplay between ROS and ER stress is controversial; ROS can either trigger the activation of ER stress or can be a consequence of ER stress [9, 12-15]. We found that NAC was able to inhibit ROS production (Fig. 3B), ER stress, cell viability and apoptosis (Fig. 5) triggered by LA, which suggests that ROS is upstream of ER stress in the induction of apoptosis by LA.

Overall, our results revealed for the first time that the natural compound LA triggered apoptotic cell death in HCT116 cells in the presence or absence of p53, which was accompanied by enhanced ROS production as well as ER stress activation. Blockage of ROS production using antioxidants such as NAC inhibited ER stress and apoptosis. Thus, our results suggested that LA induces apoptosis in colon cancer cells via ROS-mediated ER stress pathway.

\section{Acknowledgements}

This work was supported by the Research Project Supported by Shanxi Scholarship Council of China (2015-019) and grants direct from Shanxi University (113545023). 


\section{Cellular Physiology Cell Physiol Biochem 2017;42:929-938 \begin{tabular}{l|l} 
DOI: 10.1159/000478647 & Ond Biochemistry \\
Published online: June 26, 2017 & $\begin{array}{l}\text { 2017 The Author(s). Published by S. Karger AG, Basel } \\
\text { www.karger.com/cpb }\end{array}$
\end{tabular}}

Yang et al.: Levistolide A Induces Cancer Cell Apoptosis

\section{Disclosure Statement}

The authors declare that there are no conflicts of interest.

\section{References}

$>1$ Torre LA, Bray F, Siegel RL, Ferlay J, Lortet-Tieulent J, Jemal A: Global cancer statistics, 2012. CA Cancer J Clin 2015;65:87-108.

-2 Chen JR, Jia XH, Wang H, Yi YJ, Wang JY, Li YJ: Timosaponin A-III reverses multi-drug resistance in human chronic myelogenous leukemia K562/ADM cells via downregulation of MDR1 and MRP1 expression by inhibiting PI3K/Akt signaling pathway. Int J Oncol 2016;48:2063-2070.

3 Beeran AA, Maliyakkal N, Rao CM, Udupa N: The enriched fraction of Elephantopus scaber Triggers apoptosis and inhibits multi-drug resistance transporters in human epithelial cancer cells. Pharmacogn Mag 2015;11:257-268.

4 Appadath Beeran A, Maliyakkal N, Rao CM, Udupa N: The enriched fraction of Vernonia cinerea L. induces apoptosis and inhibits multi-drug resistance transporters in human epithelial cancer cells. J Ethnopharmacol 2014;158 Pt A:33-42.

5 Newman DJ, Cragg GM: Natural Products as Sources of New Drugs from 1981 to 2014. J Nat Prod 2016;79:629-661.

6 He WQ Lv WS, Zhang Y, Qu Z, Wei RR, Zhang L, Liu CH, Zhou XX, Li WR, Huang XT, Wang Q: Study on Pharmacokinetics of Three Preparations from Levistolide A by LC-MS-MS. J Chromatogr Sci 2015;53:12651273.

7 Chen F, Wang T, Wang J, Wang ZQ, Qian M: Levistolide A overcomes P-glycoprotein-mediated drug resistance in human breast carcinoma cells. Acta Pharmacol Sin 2008;29:458-464.

-8 Gorrini C, Harris IS, Mak TW: Modulation of oxidative stress as an anticancer strategy. Nat Rev Drug Discov 2013;12:931-947.

-9 Zou P, Chen M, Ji J, Chen W, Chen X, Ying S, Zhang J, Zhang Z, Liu Z, Yang S, Liang G: Auranofin induces apoptosis by ROS-mediated ER stress and mitochondrial dysfunction and displayed synergistic lethality with piperlongumine in gastric cancer. Oncotarget 2015;6:36505-36521.

10 Wang C, Zhang S, Ma R, Zhang X, Zhang C, Li B, Niu Q, Chen J, Xia T, Li P, Zhao Q Dong L, Xu C, Wang A: Roles of endoplasmic reticulum stress, apoptosis and autophagy in 2,2',4,4'-tetrabromodiphenyl ether-induced rat ovarian injury. Reprod Toxicol 2016;65:187-193.

11 Appierto V, Tiberio P, Villani MG, Cavadini E, Formelli F: PLAB induction in fenretinide-induced apoptosis of ovarian cancer cells occurs via a ROS-dependent mechanism involving ER stress and JNK activation. Carcinogenesis 2009;30:824-831.

12 Kim J, Choi TG, Ding Y, Kim Y, Ha KS, Lee KH, Kang I, Ha J, Kaufman RJ, Lee J, Choe W, Kim SS: Overexpressed cyclophilin B suppresses apoptosis associated with ROS and Ca2+ homeostasis after ER stress. J Cell Sci 2008;121:3636-3648.

13 Verfaillie T, Rubio N, Garg AD, Bultynck G, Rizzuto R, Decuypere JP, Piette J, Linehan C, Gupta S, Samali A, Agostinis P: PERK is required at the ER-mitochondrial contact sites to convey apoptosis after ROS-based ER stress. Cell Death Differ 2012;19:1880-1891.

14 Cullinan SB, Diehl JA: PERK-dependent activation of Nrf2 contributes to redox homeostasis and cell survival following endoplasmic reticulum stress. J Biol Chem 2004;279:20108-20117.

15 Haynes CM, Titus EA, Cooper AA: Degradation of misfolded proteins prevents ER-derived oxidative stress and cell death. Mol Cell 2004;15:767-776.

-16 Lee SC, Chan J, Clement MV, Pervaiz S: Functional proteomics of resveratrol-induced colon cancer cell apoptosis: caspase-6-mediated cleavage of lamin A is a major signaling loop. Proteomics 2006;6:23862394.

17 Pan D, Marcato P, Ahn DG, Gujar S, Pan LZ, Shmulevitz M, Lee PW: Activation of p53 by chemotherapeutic agents enhances reovirus oncolysis. PLoS One 2013;8:e54006.

18 Trachootham D, Alexandre J, Huang P: Targeting cancer cells by ROS-mediated mechanisms: a radical therapeutic approach? Nat Rev Drug Discov 2009;8:579-591. 


\section{Cellular Physiology Cell Physiol Biochem 2017;42:929-938

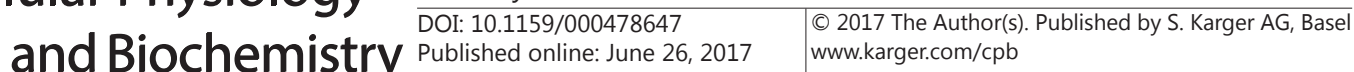

Yang et al.: Levistolide A Induces Cancer Cell Apoptosis

19 Qiu M, Chen L, Tan G, Ke L, Zhang S, Chen H, Liu J: A reactive oxygen species activation mechanism contributes to JS-K-induced apoptosis in human bladder cancer cells. Sci Rep 2015;5:15104.

20 Liu T, Wu L, Wang D, Wang H, Chen J, Yang C, Bao J, Wu C: Role of reactive oxygen species-mediated MAPK and NF-kappaB activation in polygonatum cyrtonema lectin-induced apoptosis and autophagy in human lung adenocarcinoma A549 cells. J Biochem 2016;160:315-324.

-21 Sobhan PK, Seervi M, Deb L, Varghese S, Soman A, Joseph J, Mathew KA, Raghu G, Thomas G, E S, S M, R SK: Calpain and reactive oxygen species targets Bax for mitochondrial permeabilisation and caspase activation in zerumbone induced apoptosis. PLoS One 2013;8:e59350.

-22 Tabas I, Ron D: Integrating the mechanisms of apoptosis induced by endoplasmic reticulum stress. Nat Cell Biol 2011;13:184-190.

23 Wang M, Kaufman RJ: The impact of the endoplasmic reticulum protein-folding environment on cancer development. Nat Rev Cancer 2014;14:581-597.

24 Farooqi AA, Li KT, Fayyaz S, Chang YT, Ismail M, Liaw CC, Yuan SS, Tang JY, Chang HW: Anticancer drugs for the modulation of endoplasmic reticulum stress and oxidative stress. Tumour Biol 2015;36:5743-5752.

25 Ron D, Walter P: Signal integration in the endoplasmic reticulum unfolded protein response. Nat Rev Mol Cell Biol 2007;8:519-529.

26 Sovolyova N, Healy S, Samali A, Logue SE: Stressed to death - mechanisms of ER stress-induced cell death. Biol Chem 2014;395:1-13.

27 Tang J, Ge Y, Yang L, Xu X, Sui T, Ge D, Que J, Cao X: ER Stress via CHOP Pathway is Involved in FK506Induced Apoptosis in Rat Fibroblasts. Cell Physiol Biochem 2016;39:1965-1976.

28 Puthalakath H, O'Reilly LA, Gunn P, Lee L, Kelly PN, Huntington ND, Hughes PD, Michalak EM, McKimmBreschkin J, Motoyama N, Gotoh T, Akira S, Bouillet P, Strasser A: ER stress triggers apoptosis by activating BH3-only protein Bim. Cell 2007;129:1337-1349.

29 Marciniak SJ, Yun CY, Oyadomari S, Novoa I, Zhang Y, Jungreis R, Nagata K, Harding HP, Ron D: CHOP induces death by promoting protein synthesis and oxidation in the stressed endoplasmic reticulum. Genes Dev 2004;18:3066-3077.

30 Lu M, Lawrence DA, Marsters S, Acosta-Alvear D, Kimmig P, Mendez AS, Paton AW, Paton JC, Walter P, Ashkenazi A: Opposing unfolded-protein-response signals converge on death receptor 5 to control apoptosis. Science 2014;345:98-101.

-31 Szegezdi E, Fitzgerald U, Samali A: Caspase-12 and ER-stress-mediated apoptosis: the story so far. Ann N Y Acad Sci 2003;1010:186-194.

-32 Di Sano F, Ferraro E, Tufi R, Achsel T, Piacentini M, Cecconi F: Endoplasmic reticulum stress induces apoptosis by an apoptosome-dependent but caspase 12-independent mechanism. J Biol Chem 2006;281:2693-2700. 